\title{
Análise da viabilidade de tratamento com solução coagulante orgânica da água do rio Apodi-Mossoró/RN. Ponto 3
} Larissa Fernandes da Silva* (Graduanda em Gestão Ambienta na Universidade do Estado do Rio Grande do
Norte - UERN)

Yáskara Fabíola de Monteiro Marques Leite (Professora adjunta do Departamento de Química na Universidade do Estado do Rio Grande do Norte - UERN)

Raquel Bruna Chaves de Lima (Graduanda do Curso de Ciências Biológicas na Universidade do Estado do Rio Grande do Norte - UERN)

Tamires Elizabete Monte da Silva (Graduanda em Gestão Ambienta na Universidade do Estado do Rio Grande do Norte - UERN)

*Email: Lfernandes24412@gmail.com

\section{Resumo}

Este estudo tem por objetivo comparar a eficiência da solução coagulante feita a partir do extrato de sementes da Moringa oleifera com dois coagulantes industriais muito disseminados no mercado, para tratamento da água proveniente do rio Apodi/Mossoró, referente ao seu padrão de potabilidade. A Moringa oleifera pode apresentar grande contribuição para o tratamento da água, já que suas sementes podem ser utilizadas no processo de clarificação e redução dos compostos passíveis de malefícios da mesma. O sistema de tratamento monitorado foi ensaio em equipamento Jar test, utilizando 1,5 L das amostras de água. As concentrações que apresentaram os melhores resultados para cada sistema coagulante foram: 2,5 e 7,5 mL (solução de Moringa oleifera), 7,5 e $10 \mathrm{~mL}$ (solução de cloreto férrico), 5 e 7,5 mL (solução de sulfato de alumínio). As amostras foram realizadas em triplicata. As análises foram feitas em intervalo de sedimentação de 24 horas, e os parâmetros avaliados foram turbidez (NTU), cor aparente, nitrito $\left(\mathrm{NO}_{2}\right)$, amônia $\left(\mathrm{NH}_{3}\right)$ e pH, das amostras.

Palavras-chave: soluções coagulantes; Moringa oleifera; tratamento da água, rio Apodi-Mossoró; padrão de potabilidade. 


\section{Introdução}

Recurso natural é o suprimento de alimentos, de materiais, construção, vestimenta, minerais, água, energia, tudo que é obtido da Terra e que é necessária a manutenção da vida de todas as espécies, desde a bactéria, o vírus, o fungo até o homem necessita de recursos para sobreviver. Tudo que utilizamos para sobrevivência é recurso, não só água, oxigênio, fauna, flora, mais todas as substancias que os organismos necessitam para sobreviver e reproduzir que são obtidos do meio ambiente, inclui alimentos, água, algum tipo de proteção contra agentes de estresse do ambiente: físico, tais como, temperaturas extremas, biológicas tais como, predadores, parasitas, parceiros sexuais e territórios necessários para fins de reprodução (REIS, FADIGAS \& CARVALHO, 2005).

A água é um recurso natural limitado, sinônimo de vida e desenvolvimento/crescimento, assim como tantos outros recursos naturais necessários para a existência de vida na Terra e praticamente indispensável a todas as atividades antrópicas. Com o domínio das técnicas da agricultura e da pecuária durante a pré-história, os nômades não mais se movimentavam de uma região para outra, em busca de água e alimentos. E sim, passaram a criar centros mais densamente habitados, como centros de comércio e defesa locais sempre em torno de rios e lagos, visto a necessidade de irrigação com domínio das técnicas agricultara e pecuária. Segundo Gorski (2014, p. 1): “[...] inúmeras civilizações antigas tinham como principal critério para escolher o sítio para estabelecer suas aldeias a proximidade da água, quer seja por razões funcionais, estratégicas, culturais ou patrimoniais".

No Brasil, também aconteceu assim, isto é, as populações primordiais buscaram as áreas ribeirinhas para se fixar e isso criou um cotidiano fortemente associado aos rios e córregos, relação harmoniosa que ocorreu até metade do século XX, quando então se ampliaram os conflitos entre desenvolvimento, sociedade e meio ambiente. A partir disso, ações antrópicas destruidoras poluíram e dificultaram o acesso aos corpos d'água urbanos, expulsando a prática de esportes e lazer para longe da vargem. Os centros urbanos foram se transformando, e agora o que passa a dominar o senário é a compactação do solo, rios e lagos em alto grau de poluição e contaminação contínuo, desmatamento de áreas verdes, lançamento de poluentes atmosféricos (GORSKI, 2014). A diferença da utilização dos recursos naturais entre os animais e o ser humano é que estes utilizam para sobrevivência e o outro usa para acumular bens, por isto vemos tantos problemas relacionados ao meio socioambiental.

Um exemplo vivenciado é o rio Apodi-Mossoró que percorre a cidade de Mossoró no Estado do Rio Grande Norte, esse possui importância grandiosa do ponto de vista histórico, e, era utilizado para diversos usos, desde comerciais a consumo humano, no início da povoação da cidade, que teve seu crescimento de forma rápida e desordenada em torno do mesmo, momentos que contribuíram para o senário degradante em que se encontra o corpo d'água atualmente. Que antes constituía a maior fonte de subsistência para as populações ribeirinhas da região. E de grande importância para a região oeste potiguar desde a fundação das cidades a qual o rio percorre e principalmente aquelas que têm destaque econômico para o estado como: Pau dos Ferros, Apodi, Felipe Guerra, Mossoró, Areia Branca (PETTA, MELO \& NASCIMENTO, 2010; MELO, MORAIS \& CARVALHO, 2013).

O rio Apodi-Mossoró sofre consequências e apresenta sinais visíveis de problemas ecológicos, físicos e biológicos derivadas de atividades antrópicas, que acabam constituindo-se em fonte de contaminação e ameaça ao ambiente e a saúde principalmente por ações provenientes da lixiviação de defensivos agrícolas das atividades desenvolvidas no entorno do rio; carreamento de material alóctone; além das constantes descargas de efluentes domésticos que são lançados sem prévio tratamento tornando suas águas poluídas e contaminadas, diminuição da mata ciliar e assoreamento uma vez que as margens do rio são ocupadas por construções desordenadas que acabam assoreando o rio e trazendo consequências para a população em período de chuvas, grande quantidade de material em suspensão de vírus e bactérias patogênicas (OLIVEIRA \& QUEIROZ, 2008).

Ainda assim, grande parte da população ribeirinha, que não encontra outra forma de obtenção de água, utilizam-se das águas contaminadas do rio que segundo Oliveira (2005), 2\% deles utilizam-se da água para beber, $3 \%$ para cozinhar, $29 \%$ para o banho e $32 \%$ pescam para vender e se alimentar dos peixes. Portanto, é de extrema importância o conhecimento da qualidade de suas águas superficiais, de forma a planejar o gerenciamento adequado deste recurso, avaliando impactos e prevenindo sua degradação (OLIVEIRA, SOUZA \& CASTRO, 2009; MELO, MORAIS \& CARVALHO, 2013)

O uso de coagulantes químicos é normalmente utilizado no processo de tratamento de inúmeros compostos que contêm nas águas superficiais. Tais compostos estão associados às condições higiênicosanitárias da água, e a diversos efeitos adversos à saúde. Estes agem promovendo a desestabilização de partículas no processo denominado coagulação, e após ocorre a floculação, quando as partículas desestabilizam 
e são submetidas a choques entre si, unindo-se umas às outras e formando flocos passíveis de remoção por sedimentação e/ou filtração. Nos dias atuais, tem sido objeto de estudo de diversos pesquisadores o uso de coagulantes naturais por serem de fácil manuseio e acessíveis, sendo uma alternativa de tratamento de água indispensável em regiões menos favorecidas e com carência de sistemas de tratamento de água (DI BERNARDO \& DANTAS, 2005; LIBÂNIO, 2008; ABALIWANO, GHEBREMICHAEL \& AMY, 2008; ALO, ANYIM \& ELOM, 2012).

A Moringa oleifera ultimamente esta sendo alvo de vários testes e estudos científicos, por ser considerada uma das arvores cultivadas mais úteis para o ser humano, pois todas as suas partes são possuidoras de valor benéfico para o mesmo, desde alimentar e medicinal, como folhas, frutos verdes, flores e sementes, até industrial como o óleo extraído de suas sementes, que é utilizado na lubrificação de maquinarias delicadas. A planta é pertencente à família Moringaceae, nativa do norte da Índia e presente em vários países por sua fácil propagação e adaptação a solos pobres e longos períodos de seca. Possui porte mediano, alcançando de 10 a 15 metros de altura, suas folhas possuem um comprimento de 25 a 45 centímetros, as flores são de cor branca ou bege com comprimento de 10 a 20 centímetros, e seu fruto é uma espécie de vagem com três faces e um comprimento de 20 a 60 centímetros onde em seu interior se encontram as sementes. As sementes é uma das partes principais da Moringa oleifera que apresenta eficiência no processo de coagulação da água, que no processo de tratamento não altera significativamente o $\mathrm{pH}$ da água após o tratamento e não causa problemas de corrosão (SANTOS et al., 2011; MOURA et al., 2009; GALLÃO, DAMASCENO \& BRITO, 2006; NDABIGENGESERE \& NARASIAH, 1996).

Neste contexto, o presente estudo teve como objetivo comparar a eficiência da solução coagulante feita a partir do extrato de sementes da Moringa oleifera com dois coagulantes industriais muito disseminados no mercado, para tratamento da água proveniente do rio Apodi/Mossoró, referente ao seu padrão de potabilidade.

\subsection{Caracterização da Área de Estudo}

O estado do Rio Grande do Norte possui 52.811,126 km² de área, 167 municípios, e uma população estimada de 3.408.520 no ano de 2014. Em comparação ao Censo 2000 (população estimada em 2.777.509 habitantes), em quatorze anos houve um crescimento aproximado de 18,5\%. Menos de $20 \%$ da população do estado tem o serviço de coleta de esgotos sanitários (IBGE, 2015; SILVA, 2014 apud FERREIRA, 2006).

Em Mossoró, município do Rio Grande do Norte, a população corresponde a 259.815 habitantes e possui extensão territorial de 2.099,360 km². Este situado na mesorregião Oeste Potiguar e na microrregião Mossoró, limitando-se com os municípios de Tibau, Grossos, Areia Branca, Serra do Mel, Açu, Upanema, Governador Dix-Sept Rosado, Baraúna e o Estado do Ceará. A sede do município tem uma altitude média de 16 m e apresenta coordenadas $05^{\circ} 11^{\prime} 16,8^{\prime \prime}$ de latitude sul e $37^{\circ} 20^{\prime} 38,4^{\prime \prime}$ de longitude oeste, distando da capital cerca de 277 km, sendo seu acesso, a partir de Natal, efetuado através da rodovia pavimentada BR-304. Em termos de saneamento básico, o município detém uma rede de saneamento que atende a $55 \%$ da população mossoroense. Concernente aos recursos hídricos, o município encontra-se totalmente inserido nos domínios da bacia hidrográfica Apodi-Mossoró, sendo banhado pela sub-bacia do Rio Mossoró (IBGE, 2015; O MOSSOROENSE, 2007 apud ARAÚJO, SANTOS E ARAÚJO, 2007; ARAÚJO, SANTOS E ARAÚJO, 2007).

O Rio Mossoró-Apodi que percorre o município nasce entre o estado do Rio Grande do Norte com a Paraíba, em São Brás, município de Luís Gomes, e faz um percurso de 300 quilômetros aproximadamente, atendendo a 51 municípios, desde sua nascente em Luiz Gomes até a foz, entre Areia Branca e Grossos, sendo o segundo maior rio do Estado, esse faz parte da bacia hidrográfica do rio Apodi/Mossoró também a segunda maior do Estado localizada na região oeste do estado do Rio Grande do Norte onde o clima predominante é tropical semiárido com uma precipitação pluviométrica de 400 a 600 mm anuais (JORNAL DE FATO, 2005 apud ARAÚJO, SANTOS E ARAÚJO, 2007).

\section{Materiais e Métodos}

\subsection{Ponto de Coleta em Estudo}

As amostras de água foram coletadas em um dos barramentos hidráulicos que faz a tricotomização de parte do rio que percorre o meio urbano da cidade de Mossoró, o barramento que foi tomado como ponto de referência para a coleta está localizada no bairro Barrocas como apresenta o MAPA abaixo, onde é possível observar a grande quantidade de matéria orgânica e inorgânica em suspensão na área de estudo, pela quantidade em que 
vista a planta conhecida popularmente na região como aguapé (Eichhornia crassipes), muito encontrada em corpos d'água com alto grau de poluição e contaminação. Apesar disto, muitas são as atividades desenvolvidas no rio e através deste, como: pesca, irrigação agrícola e fontes de poluição no mesmo que segundo Araújo, Santos \& Araújo (2012) são: esgoto domestico e industrial lançado que qualquer tratamento, atividade agrícola, criação de animais, lixo nas margens e olaria.

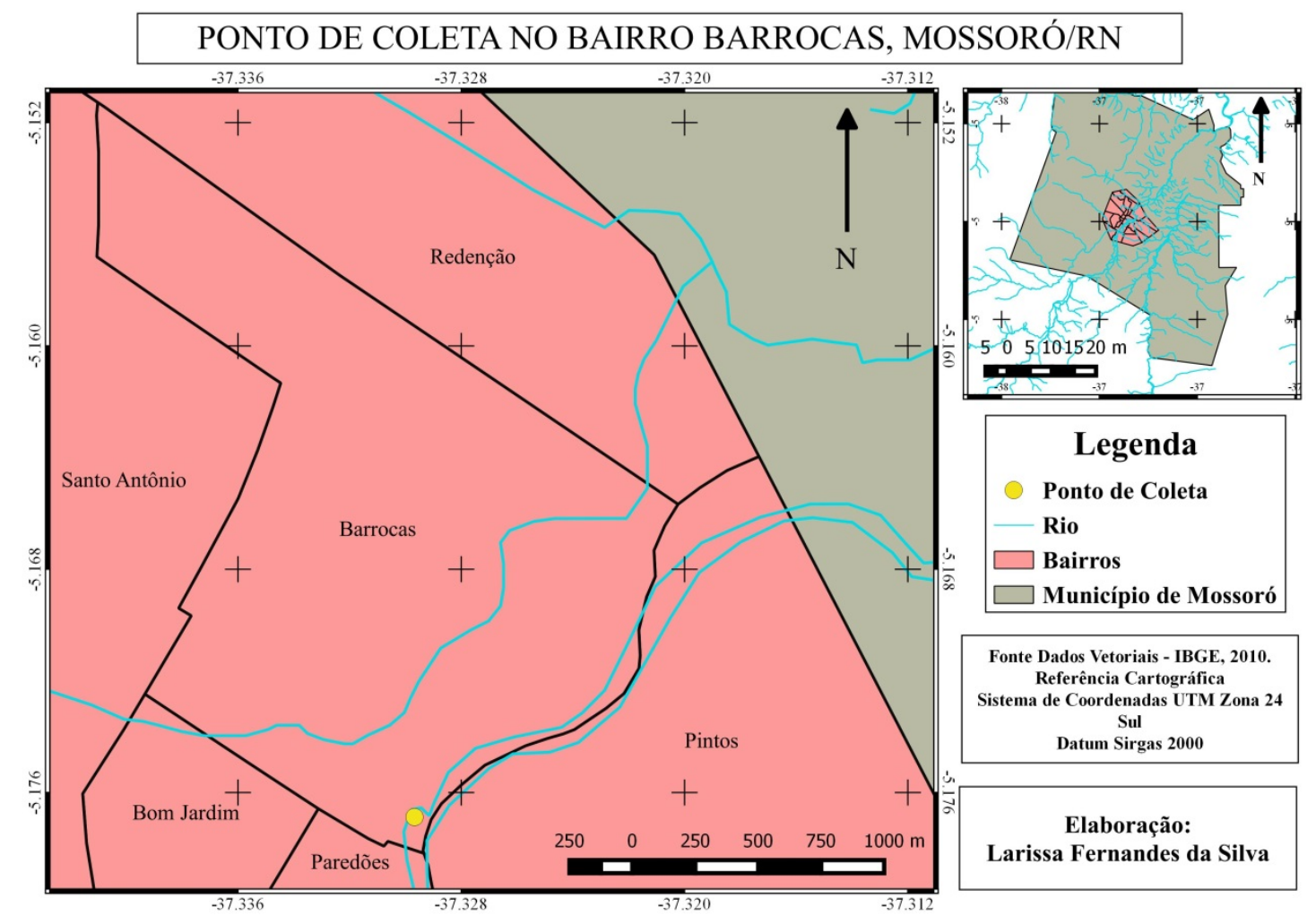

\subsection{Preparo das Soluções Coagulantes}

Foram utilizadas três diferentes soluções coagulantes para realizar este trabalho, um coagulante orgânico feito a partir do extrato das sementes de Moringa oleifera e dois coagulantes industriais obtidos com o sulfato de alumínio e o cloreto férrico.

Preparo da solução orgânica: primeiramente as sementes foram coletadas em uma área descampada localizada na área urbana de Mossoró, sendo descascadas e trituradas em mixer de 180 watts de potência. O material obtido foi levado ao forno micro-ondas por 2 minutos em potência máxima para retirada da umidade. Em seguida, para uma maior eficiência da solução coagulante, fez-se necessário a extração do conteúdo oleico das sementes em equipamento soxhlet, onde se usou hexano $\left(\mathrm{C}_{6} \mathrm{H}_{14}\right)$ como solvente orgânico extrator. A torta obtida após a extração do óleo foi utilizada como base para o preparo da solução. Minutos antes dos ensaios a solução foi preparada, utilizando-se $1 \mathrm{~g}$ da torta diluída em $100 \mathrm{ml}$ de água destilada, com 15 minutos de agitação em Agitador Magnético Modelo D1-01, para a extração do princípio ativo. Logo depois, a solução foi filtrada em papel-filtro com porosidade de $7 \mu \mathrm{m}$ (OKUDA et al., 1999).

Preparo das soluções industriais: os dois coagulantes foram preparados, utilizando-se $1 \mathrm{~g}$ de cada diluído em 100 ml de água destilada, com 15 minutos de agitação.

\subsection{Ensaios de Tratabilidade}

Antes de iniciar o trabalho foram determinadas concentrações para cada coagulante utilizado que obtiveram os melhores resultados na redução dos parâmetros analisados. Os ensaios de tratabilidade foram realizados com o equipamento Jar test, que simula os procedimentos realizados em uma Estação de Tratamento de Água - ETA com rotação rápida de 100 rpm por 3 minutos e rotação lenta de 50 rpm por 15 minutos. Foram colocados 1,5 L das amostras de água nas cubas do equipamento, e em cada uma, foram adicionadas diferentes concentrações para a Moringa oleifera (2,5 e 7,5 ml), Sulfato de Alumínio (5 e 7,5 ml) e Cloreto Férrico (7,5 e $10 \mathrm{ml}$ ). Para cada concentração de solução adicionada foram feitas três repetições, totalizando 18 ensaios. 
Para a determinação da eficiência das soluções coagulantes preparadas e das concentrações utilizadas, os parâmetros verificados foram a cor aparente, turbidez, amônia, nitrito e pH. Tais parâmetros foram analisados após o tempo de sedimentação de 24 horas com o uso do Medidor de Cor-Alfakit, TurbídimetroAlfakit, Fotocolorímetro AT100P- Alfakit e Phmetro-Kasvi.

\section{Resultados e Discussões}

Os tratamentos foram realizados em triplicata o que possibilita um resultado preciso dos parâmetros em questão e promove uma maior confiabilidade dos resultados. Antes de serem submetidas ao tratamento com as soluções coagulantes de Moringa oleifera, Cloreto Férrico e Sulfato de Alumínio, as amostras de água foram analisadas para determinação de Turbidez, Cor aparente, Potencial Hidrogeniônico $(\mathrm{pH})$, quantidade de Nitrito $\left(\mathrm{NO}_{2}\right)$ e Amônia $\left(\mathrm{NH}_{3}\right)$ como mostra o Quadro 1. De acordo com o CONAMA 357/05 os valores para turbidez (220,28 NTU), cor aparente (148,3 mg/L ) e amônia estão fora do limite máximo permitido, são esses 100 NTU, 75 $\mathrm{mg} / \mathrm{L}$ (cor aparente) e 0,02 mg/L (amônia).

Quadro 1: Valores obtidos nas amostras de água antes do tratamento com as soluções coagulantes.

\begin{tabular}{|l|c|c|}
\hline PARÂMETROS FÍSICO-QUíMICOS & VALORES DA ÁGUA BRUTA & $\begin{array}{c}\text { VALORES } \\
\text { MÁXIMOS/CONAMA }\end{array}$ \\
\hline Turbidez & $220,28 \mathrm{NTU}$ & $100 \mathrm{NTU}$ \\
\hline Cor aparente & $148,3 \mathrm{mg} / \mathrm{L}$ & $75 \mathrm{mg} / \mathrm{L}$ \\
\hline Nitrito & $0,984 \mathrm{mg} / \mathrm{L}$ & $1,0 \mathrm{mg} / \mathrm{L}$ \\
\hline Amônia & $2,428 \mathrm{mg} / \mathrm{L}$ & $0,02 \mathrm{mg} / \mathrm{L}$ \\
\hline Potencial Hidrogeniônico $(\mathrm{pH})$ & 8,45 & 6,0 a 9,0 \\
\hline
\end{tabular}

$\mathrm{O}$ pH das amostras depois do processo de tratamento (quadro 2), bem como na comparação entre todas as soluções coagulante preparadas, não apresentou variação significativa ao valor inicial $(\mathrm{pH})$. Segundo Ndabigengesere \& Narasiah (1996), o pH das amostras com tratamento do extrato das sementes de moringa não sofrem alterações significativas, mantendo-se constante no valor de $\mathrm{pH}$ 8,0.

Quadro 2: Resultados para pH, antes e após tratamento.

\begin{tabular}{|c|c|c|c|c|c|c|}
\hline \multirow{2}{*}{$\begin{array}{c}\text { Parâmetro, pH/Água } \\
\text { bruta }\end{array}$} & \multicolumn{5}{|c|}{ Coagulantes/Dosagens/ pH após tratamento } \\
\cline { 2 - 7 } & \multicolumn{2}{|c|}{ Moringa oleifera } & \multicolumn{2}{l|}{ Cloreto Férrico } & \multicolumn{2}{l|}{ Sulfato de Alumínio } \\
\cline { 2 - 8 } & $\mathbf{2 , 5} \mathbf{~ m L}$ & $\mathbf{7 , 5} \mathbf{~ m L}$ & $\mathbf{7 , 5} \mathbf{~ m L}$ & $\mathbf{1 0 ~} \mathbf{~ L}$ & $\mathbf{5 ~ m L}$ & $\mathbf{7 , 5} \mathbf{~ m L}$ \\
\hline $\mathbf{p H ~ 8 , 4 5}$ & 8,44 & 8,59 & 8,22 & 8,08 & 8,31 & 8,42 \\
\hline
\end{tabular}

Conforme mostra a Quadro 3, foi possível observar que para cada coagulante e suas respectivas concentrações, não houve diferenças significativas na redução da turbidez, no qual todos alcançaram um valor de remoção a cerca de 99\%. Ressaltando que o coagulante orgânico de moringa obteve a mesma eficiência dos coagulantes inorgânicos e remoção de cor aparente na faixa de $60 \%$. 
Quadro 3: Remoção da Turbidez e Cor aparente em \%.

\begin{tabular}{|c|l|l|l|l|l|l|}
\hline \multirow{2}{*}{ Parâmetros } & \multicolumn{5}{|c|}{ Coagulantes/Dosagens } \\
\cline { 2 - 7 } & \multicolumn{2}{|c|}{ Moringa oleifera } & \multicolumn{1}{|c|}{ Cloreto Férrico } & \multicolumn{2}{l|}{ Sulfato de Alumínio } \\
\cline { 2 - 7 } & $\mathbf{2 , 5} \mathbf{~ m L}$ & $\mathbf{7 , 5} \mathbf{~ m L}$ & $\mathbf{7 , 5} \mathbf{~ m L}$ & $\mathbf{1 0} \mathbf{~ L}$ & $\mathbf{5} \mathbf{~ m L}$ & $\mathbf{7 , 5} \mathbf{~ m L}$ \\
\hline \multirow{2}{*}{ Turbidez } & $99,35 \%$ & $98,67 \%$ & $99,40 \%$ & $99,56 \%$ & $99,60 \%$ & $99,58 \%$ \\
\hline \multirow{2}{*}{ Cor aparente } & $73,39 \%$ & $61,92 \%$ & $72,71 \%$ & $79,50 \%$ & $79,90 \%$ & $79,83 \%$ \\
\hline
\end{tabular}

O gráfico 1, 2 e 3 apresentam, os resultados das analises para os parâmetros de nitrito e amônia antes e após o tratamento. As concentrações que apresentaram melhores resultados para o tratamento feito com o coagulante orgânico do extrato das sementes de Moringa oleifera foram 2,5 mL e 7,5 mL da solução. O tratamento realizado com 2,5 mL do coagulante orgânico obteve uma redução de $50 \%(1,21 \mathrm{mg} / \mathrm{L})$ do teor de amônia, já a redução do teor de amônia com a concentração de 7,5 mL foi de $25 \%$ (1,821 mg/L). Referente ao teor de nitrito para a concentração de 2,5 mL houve uma redução de 71,62\% (0,27922 mg/L) da amostra, para a concentração de 7,5 mL o nitrito reduziu 69,15\% (0,3035 mg/L). Portanto, a concentração que obteve o melhor resultado na diminuição do teor de amônia e nitrito, foi 2,5 mL, respectivamente.

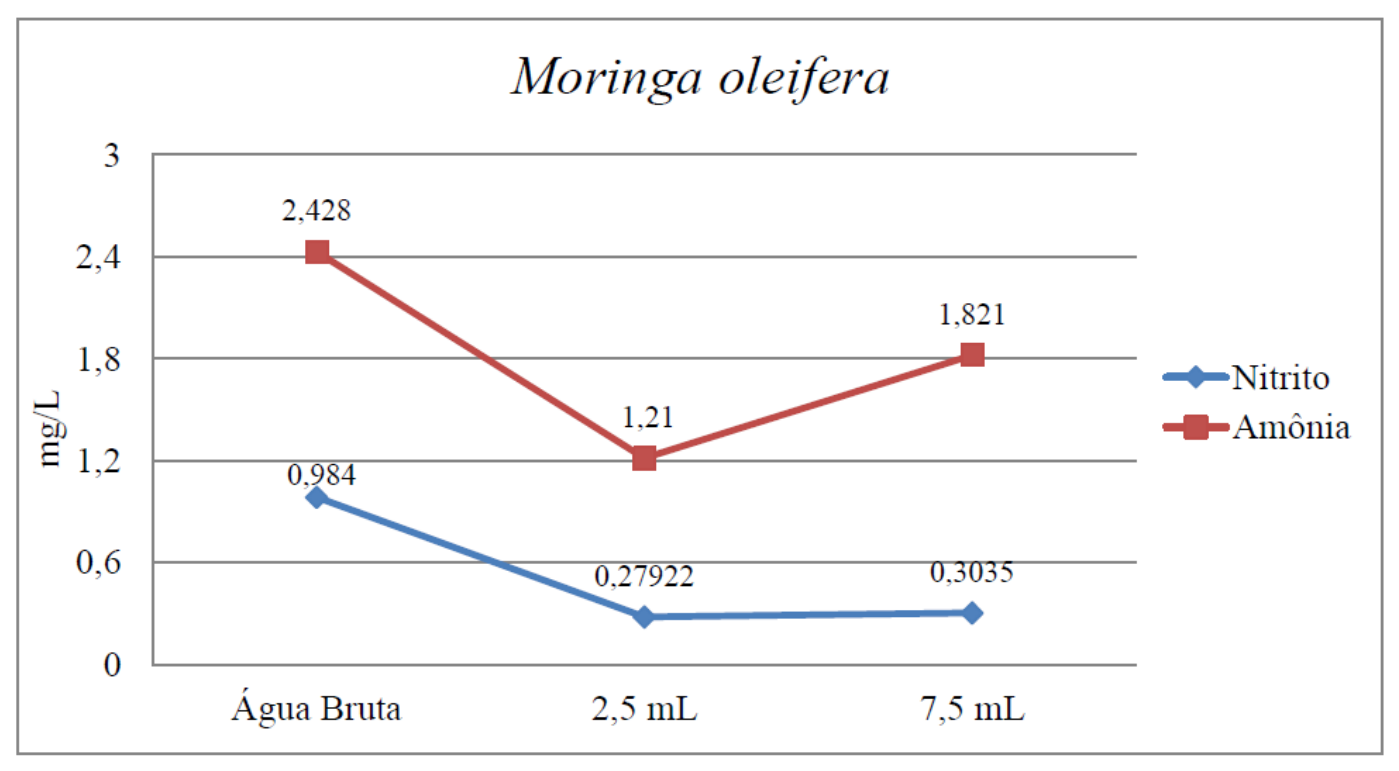

Gráfico 1- Resultados obtidos para os teores de nitrito e amônia a partir do tratamento com o coagulante orgânico feito a partir das sementes de Moringa oleifera.

O gráfico 2, mostra o tratamento com o coagulante industrial cloreto férrico para as concentrações de 7,5 mL e $10 \mathrm{~mL}$. Para a concentração de 7,5 mL a amônia reduziu 84\% (0,38848 mg/L), já para $10 \mathrm{~mL}$ a diminuição foi $85 \%$ (0,3642 mg/L). O nitrito em 7,5 mL diminuiu 56,66\% (0,4264 mg/L), e $10 \mathrm{~mL}$ a redução foi $66,66 \%(0,328 \mathrm{mg} / \mathrm{L})$. A concentração do coagulante de $10 \mathrm{~mL}$, foi a que obteve mais êxito para remoção dos dois parâmetros em análise. 


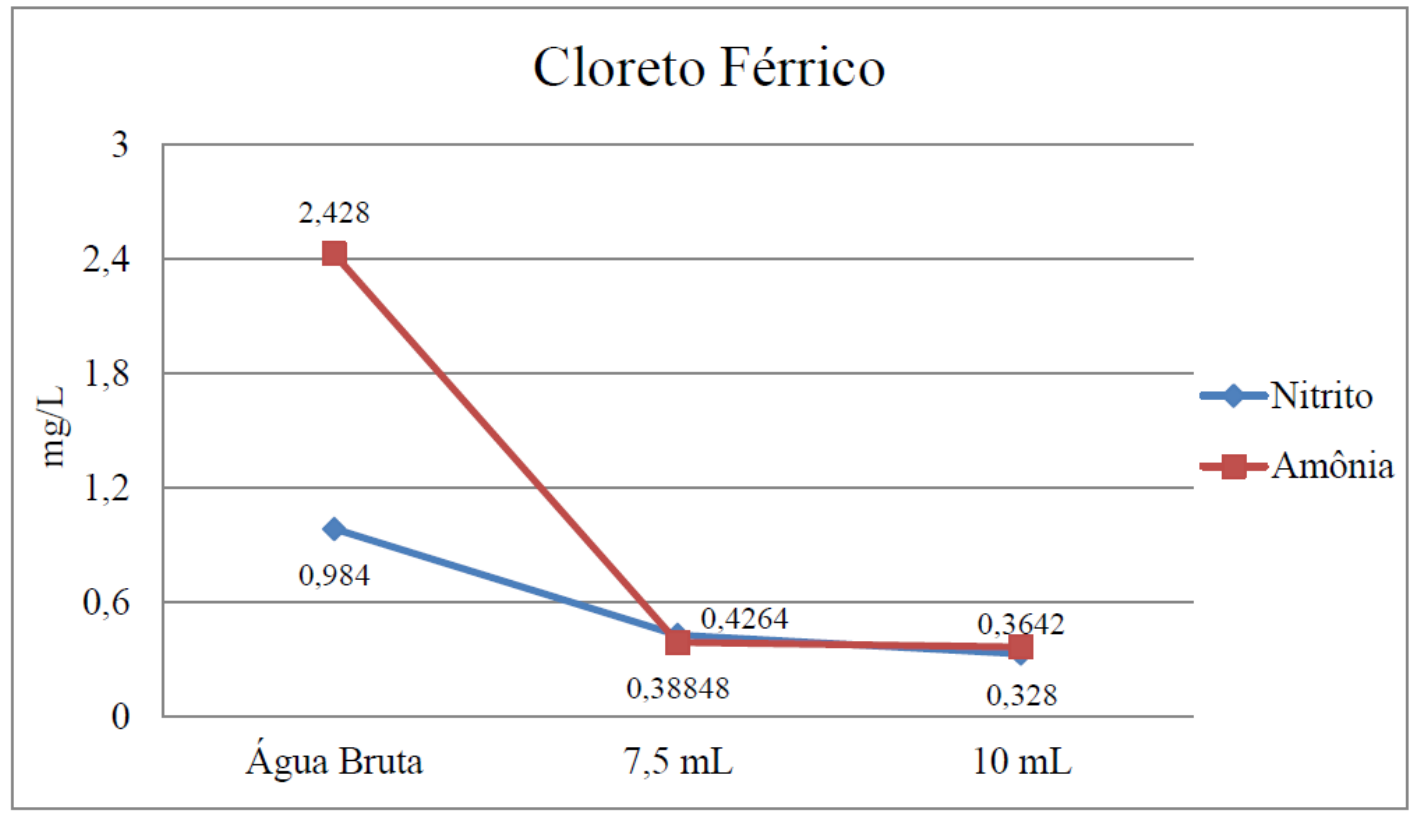

Gráfico 2- Resultados obtidos para os teores de nitrito e amônia a partir do tratamento com o coagulante industrial Cloreto Férrico.

O gráfico 3, é referente ao tratamento com o coagulante industrial sulfato de alumínio para as concentrações de $5 \mathrm{~mL}$ e 7,5 mL. A amônia reduziu 94,5\% (0,13354 mg/L), para tratamento realizado com 5 $\mathrm{mL}$ de solução, a diminuição para a concentração 7,5 mL foi $93 \%(0,16996 \mathrm{mg} / \mathrm{L})$. O nitrito reduziu 96,66\% $(0,0328 \mathrm{mg} / \mathrm{L})$ do teor para a concentração de $5 \mathrm{~mL}$, já para $7,5 \mathrm{~mL}$ a redução foi de $93,33 \%(0,0656 \mathrm{mg} / \mathrm{L})$. A melhor concentração referente à diminuição dos teores de amônia e nitrito para o tratamento com o sulfato de alumínio, foi $5 \mathrm{~mL}$.

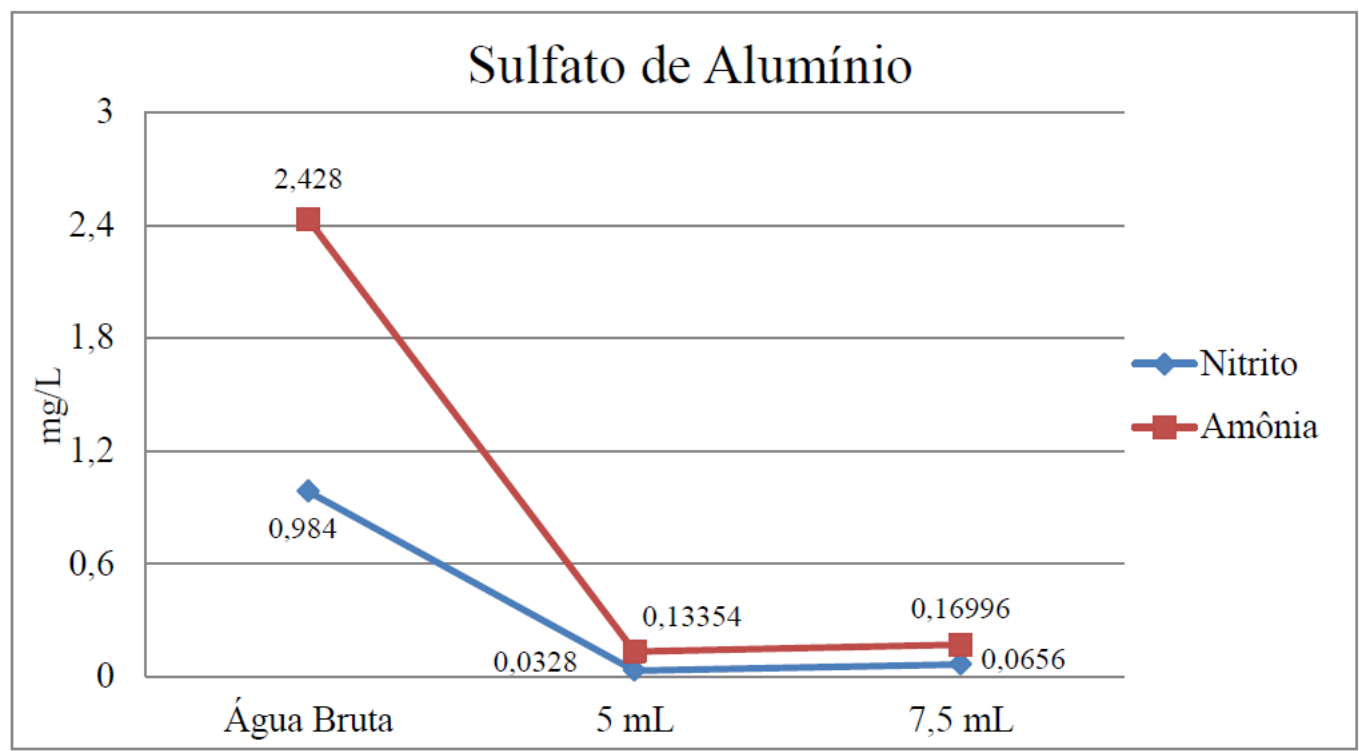

Gráfico 3- Resultados obtidos para os teores de nitrito e amônia a partir do tratamento com o coagulante industrial Sulfato de Alumínio.

Portanto, foi possível comprovar que a solução coagulante orgânica feita a partir do extrato de sementes de Moringa oleifera, possui melhor eficiência que o coagulante inorgânico cloreto férrico para duas concentrações, na remoção do teor de nitrito. O coagulante que mais se destacou foi o industrial preparado com sulfato de alumínio, que obteve a maior redução dos teores de amônia e nitrito, em todas as suas concentrações. 


\section{Conclusão}

Após o término deste trabalho, pudemos concluir que para os teores de turbidez e cor aparente analisados após o tratamento com cada uma das soluções e para todas as concentrações utilizadas não houve uma discrepância, no qual todos alcançaram um valor de remoção de turbidez cerca de $99 \%$ e valores de cor aparente na faixa de $60 \%$. Para o pH, o mesmo aconteceu não houve diferença significativa antes e após o tratamento entre os coagulantes e suas concentrações específicas.

Portanto, foi possível comprovar que a solução coagulante orgânica feita a partir do extrato de sementes de Moringa oleifera, possui melhor eficiência que o coagulante inorgânico cloreto férrico em duas concentrações, na remoção do teor de nitrito. O coagulante que mais se destacou foi o industrial feito com sulfato de alumínio, que obteve a maior redução dos teores de amônia e nitrito, em todas as suas concentrações. O coagulante e a concentração que obteve o melhor resultado na diminuição do teor de nitrito, foi o coagulante feito a partir do extrato das sementes de Moringa oleifera para a concentração de 2,5 mL. Isso mostra que um produto natural, encontrado com certa facilidade e de baixo custo tem um potencial de melhora da qualidade de água tão importante e escassa no semiárido potiguar, comparável ao de coagulantes industriais amplamente usados no mercado.

\section{Analysis of the feasibility of treatment with organic coagulante solution of the water from Apodi-Mossoró/RN. Ponto 3}

\section{Abstract}

This study has as a goal to compare the efficiency of the coagulant solution made from extract of Moringa oleifera seeds with two industrial coagulants very disseminated in the Market, for treatment of the water from Apodi/Mossoró river, relative to its pattern of potability. Moringa oleifera can present a big contribution for water treatment, because the seeds can be used in the process of clarification and reduction of the harmful compounds in it. The monitored treatment system was done in a Jar test equipment using 1,5 L of the water samples. The concentrations that had shown the best results for each coagulante system wer: 2,5 and 7,5 mL (Moringa oleifera solution), 7,5 and $10 \mathrm{~mL}$ (solution of ferric chloride), 5 and 7,5 mL (solution of aluminum sulfate). The samples were made in triplicate. The analysis were made in a 24 hour sedimentation break, and the parameters evaluated were turbidity (NTU), aparent color, nitrite $\left(\mathrm{NO}_{2}\right)$, ammonia $\left(\mathrm{NH}_{3}\right)$ and $\mathrm{pH}$ of the samples.

Keywords: coagulante solution; Moringa oleifera; water treatment; Apodi-Mossoró river; potability pattern.

\section{Referências Bibliográficas}

ABAliwanO, J. K.; GHEBREMiChAEL, K. A.; AMY, G. L. Application of the purified Moringa oleifera coagulant for surface water treatment. WaterMill Working Paper Series, n. 5, p. 1-19, 2008.

ALO, M. N.; ANYIM, C.; ELOM, M. Coagulation and antimicrobial activities of Moringa oleifera seed storage at $3^{\circ} \mathrm{C}$ temperature in turbid water. Advances in Applied Science Research, v. 3, n. 2, p. 887-894, 2012.

ARAÚJO, V. S.; SANTOS, J. P.; ARAÚJO, A. L. C. Monitoramento das águas do rio Mossoró/RN, no período de abril/2005 a julho/2006. Holos, V.1, p. 4-41, 2007.

CONAMA. Conselho Nacional do Meio Ambiente. Resolução No 357 de 17 de março de 2005.

DI BERNARDO, L.; DANTAS, A. D. B. Métodos e técnicas de tratamento de água. 2. ed. São Carlos: RiMa, p. 792, 2005. 
FERREIRA, D. M. Avaliação do índice da Qualidade da Água da Escola Agrícola de Jundiaí. Natal, 2006.

GALLÃO, M. I.; DAMASCENO, L. F.; BRITO, E. S. Avaliação química e estrutural da semente de Moringa. Revista Ciência Agronômica, v. 37, n. 1, p. 106-109, 2006.

GORSKI, M. C. B. Rios e cidades: ruptura e reconciliação. 2008. 237 f. Dissertação (Mestrado em Arquitetura e Urbanismo) - Universidade Presbiteriana Mackenzie, São Paulo. 2008.

IBGE - Instituto Brasileiro de Geografia e Estatística. Informações completas sobre as cidades. Disponível em <http://www.cidades.ibge.gov.br/xtras/perfil.php?lang=\&codmun=240800\&search=rio-grande-donorte|mossoro|infograficos:-informacoes-completas> Acesso em: 01 de setembro de 2015.

LIBÂNIO, M. Fundamentos de qualidade e tratamento de água. 2. ed. Campinas: Editora Átomo, p. 444, 2008.

MELO, K. K. P.; MORAIS, J. A.; CARVALHO, M. V. C. Participação e planejamento integral do meio urbano de Mossoró/RN: contribuições a problemática ambiental do rio Apodí-Mossoró. In: II Seminário de Direitos Humanos: construindo uma cultura de direitos no semiárido, Mossoró/RN, 2013.

MOURA, A. S.; SOUSA, A. L. G.; OLIVEIRA JUNIOR, A. M.; LIRA, M. L.; SILVA, G. L. Caracterização físico-química da folha, flor e vagem da Moringa (Moringa oleifera Lamarck). In: ENCONTRO NACIONAL DE MORINGA, 1., 2009, Aracaju. Anais... Aracaju: ENAM, 2009.

NDABIGENGESERE, A.; NARASIAH, S. K. Influence of operating parameters on turbidity removal by coagulation with Moringa oleifera seeds. Environmental Technology, v. 17, p. 1103-1112, 1996.

OKUDA, T. BAES, A,U.; NISHIJIMA,W.; OKADA, M. Improvement of extraction method of coagulation active components from Moringa oleifera seed. Water Research, v. 31, p. 3373-3378, 1999.

OLIVEIRA, M. A.; QUEIROZ, R. A. C. A Poluição do Rio Mossoró (RN) e a Ação Intervencionista do Ministério Público. In: ENCONTRO NACIONAL DA ANPPAS, 4., 2008, Brasília. Anais..., Brasília: Anppas, 2008.

OLIVEIRA, T. M. B. F.; SOUZA, L. D.; CASTRO, S. S. L. Dinâmica da série nitrogenada nas águas da bacia hidrográfica Apodi/Mossoró - RN - Brasil. Eclética Química, São Paulo, v. 34, n. 3, p. 17-26, 2009.

PETTA, R. A.; MELO, A. C.; NASCIMENTO, P. S. R. Subsídio à gestão ambiental do rio Apodi-Mossoró na área urbana de Mossoró - RN. Geografia (Londrina) v. 19 n. 2, p. 127-144, 2010.

REIS, L. B; FADIGAS, E. A. A; CARVALHO, C. E. Energia, recursos naturais e a prática do desenvolvimento sustentável. Barueri, SP: Manole, 2005.

SANTOS, W. R.; MATOS, D. B.; OLIVEIRA, B. M.; SANTANA, T. M.; SANTANA, M. M.; SILVA, G. F. Estudo do tratamento e clarificação de água com torta de sementes de Moringa oleifera Lam. Revista Brasileira de Produtos Agroindustriais, Campina Grande, v. 13, n. 3, p. 295-299, 2011. 